\title{
Breast Self-Examination and Health Seeking behavior of Women in Leku Town, Sidama Region, Southern Ethiopia
}

\author{
Lalisa Gemechu Bona ${ }^{1 *}$, Dereje Geleta Negera ${ }^{2}$ and Alemu Tolcha Kereba ${ }^{1}$ \\ ${ }^{1}$ Department of Environmental Health, Hawassa University College of medicine and Health sciences, Ethiopia
}

${ }^{2}$ School of public health, Hawassa University College of medicine and Health sciences, Ethiopia

*Corresponding author: Lalisa Gemechu Bona, Department of Environmental Health, Hawassa University College of medicine and Health sciences, Ethiopia

\begin{tabular}{|c|c|}
\hline ARTICLE INFO & ABSTRACT \\
\hline $\begin{array}{l}\text { Received: 幽June 11, } 2021 \\
\text { Published: 幽 June 28, } 2021\end{array}$ & $\begin{array}{l}\text { Breast cancer is the second most common cancer related death next to lung cancer } \\
\text { amongwomen in the world and most of African countries, including Ethiopia. In developing } \\
\text { countries like Ethiopia, mortality rate is higher than that of developed countries because } \\
\text { patients are found in advanced stage of the disease, where little or nothing can be done. }\end{array}$ \\
\hline $\begin{array}{l}\text { Citation: Lalisa Gemechu Bona, Dere- } \\
\text { je Geleta Negera, Alemu Tolcha Kereba. } \\
\text { Breast Self-Examination and Health Seek- } \\
\text { ing behavior of Women in Leku Town, } \\
\text { Sidama Region, Southern Ethiopia. Bi- } \\
\text { omed J Sci \& Tech Res 36(5)-2021. BJSTR. } \\
\text { MS.ID.005911. } \\
\text { Keywords: Breast Cancer; Leku Town; } \\
\text { Breast Self-Examination; Shebedino } \\
\text { Woreda }\end{array}$ & $\begin{array}{l}\text { To assess the awareness of breast cancer, breast self-examination practice and health } \\
\text { seeking behavior for breast cancer among women in Leku town, Sidama Region, southern } \\
\text { Ethiopia. A community based cross sectional study was employed. Systematic random } \\
\text { sampling technique was used as a data collection technique. Structured and semi- } \\
\text { structured questionnaire was used and data collectors were trained on data collection } \\
\text { process and techniques in order to collect valid information to meet the proposed study } \\
\text { objectives. About } 206(61.31 \%) \text { women, who participated on this study, have ever heard } \\
\text { about breast cancer. From these only } 28(13.6 \%) \text { were found to have good knowledge. } \\
\text { Nearly about half } 102(49.5 \%) \text { of the women, who are informed about breast cancer, } \\
\text { believe that early detection of breast cancer improves survival. The result showed, out } \\
\text { of the women who reported to have had breast cancer information, } 94(45.6 \%) \text { have } \\
\text { ever heard/read about breast self-examination, but only } 13(13.8 \%) \text { practice breast self- } \\
\text { examination and } 256(76.2 \%) \text { of the participant have a positive health seeking behavior. } \\
\text { The study participants have very poor knowledge about breast cancer. Furthermore, low } \\
\text { and improper breast self-examination practice was observed. }\end{array}$ \\
\hline
\end{tabular}

\section{Introduction}

Breast cancer is the commonest cancer and the second most common cancer related death next to lung cancer among women in the world and most of African countries. In Ethiopia, it is the second common cancer among women next to cervical cancer with estimated incidence rate of 19.5 per 100,000 and estimated death rate of 11.8 per 100,000 females are reported [1]. American Cancer Society (2010) reported that breast cancer is the leading cause of cancer death among women in Southern Africa (9,000 cases, 4,500 deaths) and Northern Africa (28,000 cases, 14,600 deaths). The report also showed that currently breast cancer has become

the most commonly diagnosed cancer in women in Sub-Saharan African countries and its incidence rates have nearly doubled over the past two decades. According to the top ten cancer burdens classifications by topography and sex in Addis Ababa city, breast cancer was one of the commonest cancers and accounts for 617 cases (583 females and 34 males) out of 1769 cancer cases [2].

Although breast cancer prevalence in developed countries is more than developing countries, the majority of breast cancer mortality (69\%) occurs in developing countries like Ethiopia [3]. The mortality rate and survival rate of the disease depends on the 
stage of the disease at presentation. The 2927 incident cases of breast cancer identified in 2002 had the following distribution by stage: stage 0 (in situ), 424(14\%); stage I, 1118 (38\%); stage II, 938 (32\%); stage III, 233 (8\%); stage IV, 123 (4\%); unknown, 91 (3\%) [4]. Breast cancer risk factors among Ethiopian women are not well known because of small number of studies conducted on this area. The burden of the disease is not easy to estimate according to hospital and health facility reports; because thousands of breast cancer cases remain unreported as women living in rural areas often seek treatment from traditional healers before seeking help from health facilities [5].

Among the early breast cancer detection methods, Breast SelfExamination (BSE) is cost-effective, especially in resource poor countries. American Cancer Society recommends monthly practice as an option for women starting from early 20s. More than $90 \%$ of cases of breast cancer can be detected by women themselves, stressing the importance of BSE as the key breast cancer detection mechanism. In Ethiopia, poor awareness of breast cancer symptoms and lack of practice of BSE has usually been associated with patient delay in seeking help resulting in reduced survival, more aggressive disease and fewer treatment options [6].

\section{Methods and Materials}

\section{Study Area}

The study was conducted in one of the randomly selected semiurban; kebele' (the smallest administrative hierarchy) of Leku town found in Sidama Region, south Ethiopia. Leku is one of the towns in Shebedino 'woreda' which is the second higher administrative structure equivalent to county and lower than zonal administrative structure. There is only one health center providing service to 34,379 people in and around the town. The center provides general and specific services and had adequate transportation facility for referral cases to the nearby town district hospitals or other health facilities. The number of deliveries attended with skilled birth attendant in the first half of 2016 was 370 (62.1\% of the plan). Users of all types of family planning of the town in the first 6 months of 2016 was $95.6 \%$. The number of mothers who received early postnatal care (within 7 days) in the first 6 months of 2016 were 399 ( $67 \%$ of the plan). There is no cancer treatment service in this town (Shebedino Woreda Health Bureau, 2017).

\section{Study Design and Study Period}

A community based cross sectional study was employed.

\section{Population}

A. Source Population: All women in Leku town.

B. Study Population: All women in the Leku town who are 20 years old and above, who have resided in the town for at least six months.

C. Study Unit: Randomly selected woman is participated in the study. At the beginning, the household was randomly selected and the women in that household who are above 20 years of age were randomly contacted for data collection depending on the inclusion criteria.

\section{Inclusion and Exclusion Criteria}

A. Inclusion Criteria: Women who have been residing in the town for at least six months.

B. Exclusion Criteria: All women who are critically ill and unable to communicate for any reasons during the data collection time.

\section{Sample Size}

Sample size was determined by using a single population proportion formula and calculated taking 95\% confidence interval and 5\% marginal error and good Knowledge on breast cancer and BSE as $34.7 \%$ from a study done among women in Northern Ethiopia [7], the final sample size, by adding $10 \%$ non-response rate, was 363 .

\section{Study Variable}

A. Dependent Variable: Knowledge of Breast Cancer, Practice of BSE, Health seeking Behavior of women.

B. Independent Variable: Socio-demographic characteristics, Family History of Breast cancer, Previous Breast Problem.

\section{Data collection and Quality Control}

Data was collected by trained data collectors. Data collectors were well informed about the study to provide a sufficient information or informed consent for respondents to get reliable data. On-site supervision was carried out by supervises to check the completeness, accuracy and consistency and corrective measures was taken when needed. The questionnaire was prepared in English language and translated to local language to make the data collection easier and understood by respondents. Before the actual data collection, pretest was conducted on the $5 \%$ of sample size. The contents of the questionnaire were modified based on the result of pretest.

\section{Results}

The study participants lie between the age of 20 and 79 years; with the mean age of 32.54 years. But majority (153 (45.5\%)) of them are between $20-29$ year of age. Two hundred fifty-one $(74.7 \%)$ of the women are married, 62 (18.5\%) are single, 261 (77.7\%) are protestant, 45 (13.4\%) are orthodox, and 26 (7.7\%) are Muslims (Table 1). Most $(88(26.5 \%)$ of the study participants cannot read and write; and are housewives (141(41.9\%)) (Table 1). Out of all the respondents $5(1.5 \%)$ have a family history of breast cancer and $13(3.8 \%)$ reported that they had breast problem at least once in their life. 
Table 1: Socio-demographic characteristics of women in Yiraba Town, Sidama Region, SNNPR, Ethiopia, August 2020.

\begin{tabular}{|c|c|c|c|}
\hline Demographic Characteristics & Category & Frequency & $\%$ \\
\hline \multirow{4}{*}{ Age } & $20-29$ & 153 & 45.5 \\
\hline & $30-39$ & 89 & 26.5 \\
\hline & $40-49$ & 55 & 16.4 \\
\hline & $>50$ & 39 & 11.6 \\
\hline \multirow{4}{*}{ Religion } & Orthodox & 45 & 13.4 \\
\hline & Protestant & 261 & 77.7 \\
\hline & Islam & 26 & 7.7 \\
\hline & Others & 4 & 1.2 \\
\hline \multirow{4}{*}{ Marital Status } & Married & 251 & 74.7 \\
\hline & Single & 62 & 18.5 \\
\hline & Divorce & 7 & 2.1 \\
\hline & Widowed & 16 & 4.7 \\
\hline \multirow{5}{*}{ Educational Status } & Can't read and write & 89 & 26.5 \\
\hline & Can read and write & 38 & 11.3 \\
\hline & Primary & 58 & 17.3 \\
\hline & Secondary & 80 & 23.8 \\
\hline & College and above & 71 & 21.1 \\
\hline \multirow{5}{*}{ Occupation } & Housewife & 141 & 41.9 \\
\hline & Government employee & 35 & 10.4 \\
\hline & Student & 58 & 17.3 \\
\hline & Merchant & 59 & 17.6 \\
\hline & Others & 43 & 12.8 \\
\hline
\end{tabular}

\section{Knowledge of Breast Cancer}

Two hundred six $(61.31 \%)$ of the study participants revealed that they have heard about breast cancer. Seventy-six $(36.9 \%)$ of them got the information from TV and/or Radio, while 56(27.2\%) is from health professionals and $36(17.5 \%)$ from friends (Figure 1). The overall knowledge score of the 206 respondents who have heard about breast cancer ranged from 2 to 26, with a mean score of 10.9 (SD = 4.706), out of the 30 questions designed to assess knowledge about breast cancer. According to the knowledge score assessment method, only 28(13.6\%) were found to had good knowledge and 178 (86.4\%) had poor knowledge. Majority of the women identified family history of breast cancer, smoking and not breast feeding as risk factors for breast cancer in the order $129(62.6 \%), 98(47.6 \%)$ and 86 (41.7\%) respectively. And the least identified risk factors were high fat diet $13(6.3 \%)$, late menopause $22(10.7 \%)$ and early menarche 32(15.5\%). Breast lump, ulceration and soreness of breast and breast pain was identified as the major symptoms of breast cancer by 163 (79.1\%), 105 (50.9\%) and 96 (46.6\%) respondents respectively (Table 2).

Table 2: Risk factors for breast cancer mentioned by women in Leku Town, Sidama Region, Ethiopia August 2020.

\begin{tabular}{|c|c|c|c|c|}
\hline No. & & Characters & Freq. & $\%$ \\
\hline \multirow{11}{*}{1} & \multirow{11}{*}{ Risk Factors } & Old age & 59 & 28.6 \\
\hline & & Family history of breast cancer & 129 & 62.6 \\
\hline & & Early menarche before age of 12 & 32 & 15.5 \\
\hline & & Late menopause after age of 55 & 22 & 10.7 \\
\hline & & First child above 30 & 34 & 16.5 \\
\hline & & Nulliparity & 55 & 26.7 \\
\hline & & Not breast feeding & 86 & 41.7 \\
\hline & & Cigarette smoking & 98 & 47.6 \\
\hline & & Alcohol abuse & 40 & 19.4 \\
\hline & & High fat diet & 13 & 6.3 \\
\hline & & I don't know & 10 & 4.9 \\
\hline
\end{tabular}




\begin{tabular}{|c|c|c|c|c|}
\hline \multirow{8}{*}{2} & \multirow{8}{*}{ Sign And Symptoms } & Breast lump & 163 & 79.1 \\
\hline & & Nipple discharge & 72 & 35 \\
\hline & & Dimpling in the breast skin & 50 & 24.3 \\
\hline & & Change in appearance of breast skin & 66 & 32 \\
\hline & & Breast pain & 96 & 46.6 \\
\hline & & Lump under armpit & 31 & 15.1 \\
\hline & & Nipple retraction & 62 & 30.1 \\
\hline & & Ulceration and soreness in the breast & 105 & 50.9 \\
\hline
\end{tabular}

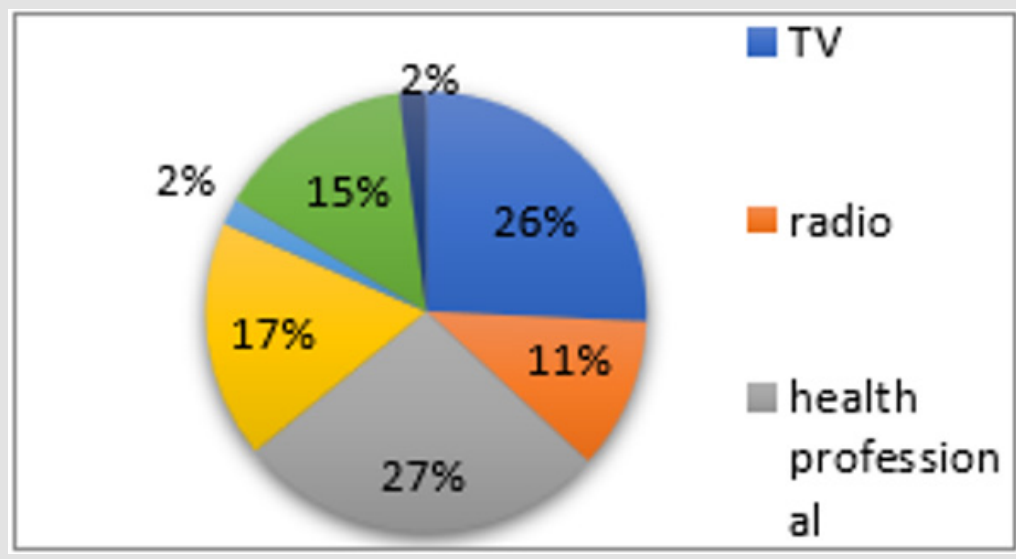

Figure 1: Source of information about breast cancer of women in Town, Sidama Region, Ethiopia, August 2020.

Concerning the etiology of breast cancer, about $88(42.7 \%)$ think that breast cancer is inherited, whereas, 50 (24.3\%) of the women think the cause is infection (Figure 2). About 102(49.5\%) believe that early detection of breast cancer improves survival and treatment outcome (data not available). Majority (104(50.5\%) of the study participants don't know the screening methods of breast cancer. Among the participants who had ever heard about breast cancer $46(22.3 \%)$ said BSE is one of the screening methods, while 93(45.1\%) identified CBE as the screening method. Mammography was known by very few $24(11.7 \%)$ respondents. Regarding the treatment, most women $139(67.5 \%)$ identified surgery as a treatment option of breast cancer, while $69(33.4 \%)$ of them identified chemotherapy as a treatment option and 62(30.1) identified radiotherapy (Figure 3).

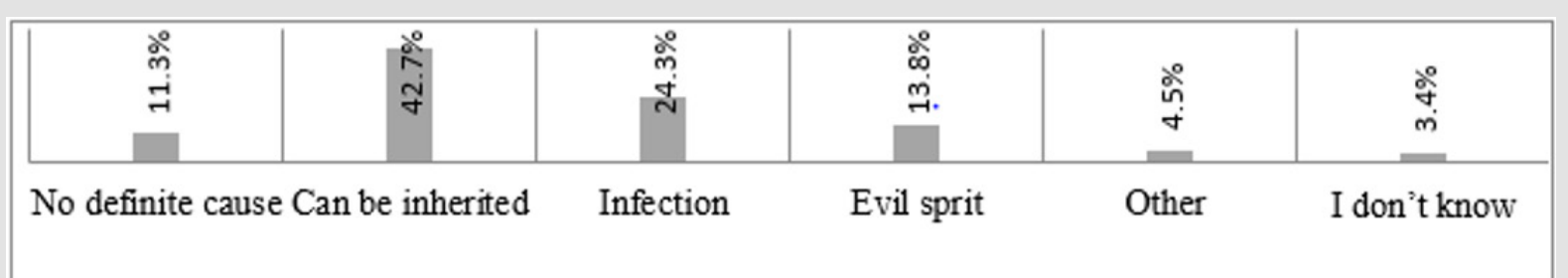

Figure 2: Causes of breast cancer mentioned by women in Leku town, Sidama Region, Ethiopia, and August 2020.

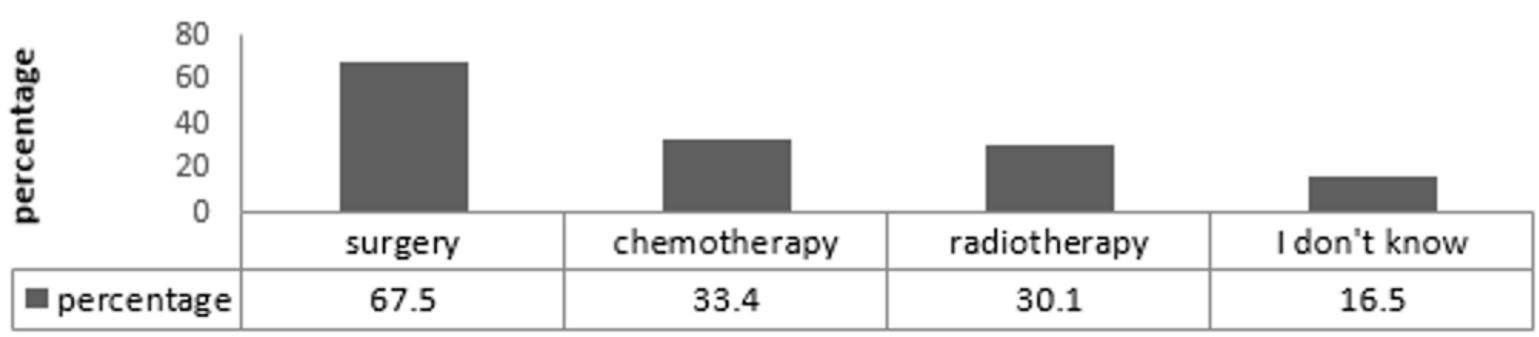

Figure 3: Treatment options of breast cancer by women in Leku town, Sidama Region, Ethiopia, August 2020. 


\section{Practice about Breast Self-Examination}

Out of the women who reported to have had breast cancer information, 94(45.6\%) have ever heard about BSE. The major source of information on BSE was media (television and /or radio) $36(38.3 \%)$, and health professionals $39(41.5 \%)$. Out of these women only $37(39.3 \%)$ know how to perform BSE and actually only

Table 3: BSE practice in Leku town, Sidama Region, Ethiopia, August, 2020.

\begin{tabular}{|c|c|c|c|c|}
\hline S.No & Characters & Categories & Freq. & $\%$ \\
\hline \multirow{4}{*}{1} & \multirow{4}{*}{ When do you perform BSE } & While I am on menses & 0 & 0 \\
\hline & & A day after my menses & 0 & 0 \\
\hline & & A week after my menses & 4 & 30.7 \\
\hline & & Any time & 9 & 69.3 \\
\hline \multirow{3}{*}{2} & \multirow{3}{*}{ Age you started to perform BSE } & 20 & 3 & 23 \\
\hline & & $21-29$ & 8 & 61.5 \\
\hline & & $30<$ & 2 & 15.3 \\
\hline \multirow{5}{*}{3} & \multirow{5}{*}{ Frequency of BSE performance } & Weekly & 0 & 0 \\
\hline & & Monthly & 3 & 23 \\
\hline & & In regular interval(others) & 2 & 15.3 \\
\hline & & Occasionally & 6 & 46.1 \\
\hline & & When I see abnormality & 2 & 15.3 \\
\hline
\end{tabular}

Table 4: Reason not to practice BSE in Leku town, Sidama Region, Ethiopia, August 2020.

\begin{tabular}{|c|c|c|c|}
\hline No. & Reason & Freq. & \% \\
\hline 1 & I do not have breast problem & 17 & 70.8 \\
\hline 2 & I do not think I should & 31.6 & 10 \\
\hline 3 & I do not feel comforting doing it & 5 & 5 \\
\hline 4 & Other & 20.5 \\
\hline
\end{tabular}

\section{Health Care Seeking Behavior}

From 336 participants involved in this study, 256 (76.2\%) women feel positive about visiting a health center for any problems they detect in their breast (Figure 4). From the women who have heard about breast cancer 136 (45.6\%) said breast cancer treatment is given at hospital level. Twelve (5.8\%) of them \& 46 $(22.3 \%)$ of them also said breast cancer treatment is given in a

Table 5: Reasons for not visiting health facilities in Leku Town, Sidama Region, Ethiopia, August 2020.

\begin{tabular}{|c|c|c|}
\hline Reasons & Freq. & $\%$ \\
\hline I don't think it is a serious problem. & 32 & 40 \\
\hline I don't know which health facilities provide treatment. & 3 & 3.8 \\
\hline I don't have enough money to visit health center. & 20 & 25 \\
\hline I am not comfortable to have my breast examined by male physicians. & 2 & 2.5 \\
\hline I am afraid of the diagnosis and / or treatment of breast cancer. & 6 & 7.5 \\
\hline I think I will get better treatment from traditional healers. & 27 & 33.7 \\
\hline Others & 26 & 32.5 \\
\hline
\end{tabular}

private clinic and health center respectively. The rest didn't know where the treatment is given. Among these women 92(44.7\%) do not have any idea about the cost of breast cancer treatment. About $40(19.4 \%)$ of the women think it is affordable somehow; whereas 74 (35.9\%) women think it is expensive and not easily available. The reason for most women not to visit a health facility was not considering breast abnormalities as a serious problem 32 (40\%) (Table 5).
(13.8\%) practice BSE. Concerning the initiation of BSE practice, stated the practice a week after menses. But only 3 women $(23 \%)$ practice BSE regularly (monthly), while 12(42.9\%) of them do it occasionally in an irregular pattern (Table 3 ). The main reasons for most $(17(70.8 \%))$ of the women not to practice BSE is not having breast problem (Table 4). 


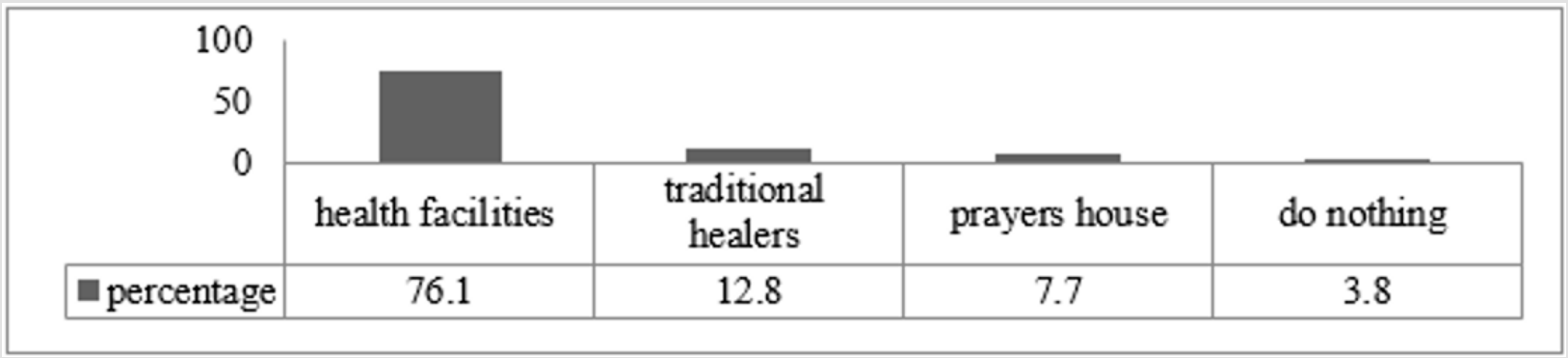

Figure 3: Treatment place preference for breast problem of women in Leku Town, Sidama Region, Ethiopia, August 2020.

\section{Factors Determining Knowledge and Practices}

The odds ratios of each explanatory variable with the outcome variable (knowledge of breast cancer, BSE practice and health seeking behavior) were assessed for their association. The result revealed that women who have formal education had 8 times more likely to have good knowledge than those who do not have formal education. Women who have family history of breast cancer and self-history of breast problem were 10 and 5 times more likely to have good knowledge than those who do not have, respectively (Table 6). Participants who have good knowledge of breast cancer are practicing BSE 7 times more than those who have poor knowledge (Table 7).

Table 6: Association of age and education with knowledge of breast cancer in Leku Town, Sidama Region, Ethiopia, August 2020.

\begin{tabular}{|c|c|c|c|c|}
\hline \multirow{2}{*}{ Characteristics } & Category & Good & Knowledge & \multirow{2}{*}{ OR 95\% CI } \\
\cline { 2 - 4 } & Formal education & 27 & 137 & $8.080(1.065,61.290)$ \\
\hline \multirow{2}{*}{\begin{tabular}{c} 
Education status \\
\cline { 2 - 4 }
\end{tabular}} & No formal education & 1 & 41 & $10.560(1.681,66.331)$ \\
\hline $\begin{array}{c}\text { Family history of breast } \\
\text { cancer }\end{array}$ & Yes & 3 & 25 & \\
\cline { 2 - 5 } & No & 3 & 4 & $5.220(1.103,24.706)$ \\
\hline $\begin{array}{c}\text { Self-history of any breast } \\
\text { problem }\end{array}$ & Yes & 25 & 174 & \\
\hline
\end{tabular}

Table 7: Association of breast cancer knowledge with BSE practice in Leku Town, Sidama Region, Ethiopia, August 2020.

\begin{tabular}{|c|c|c|c|}
\hline \multirow{2}{*}{ Character } & \multirow{2}{*}{ BSE practice } & \multicolumn{2}{|c|}{ OR 95\% CI } \\
\cline { 2 - 4 } & Category & 16 & 10 \\
Knowledge of breast cancer & Good & 12 & $5.467(2.729,20.428)$ \\
\cline { 2 - 4 } & Poor & 56 & 10 \\
\hline
\end{tabular}

\section{Discussion}

This research was conducted among 363 women in Leku town and has a response rate of $92.6 \%$. As is the case in different other research findings, there is a general knowledge deficit about breast cancer. The total number of women who have heard about breast cancer was found to be 206 (61.31\%). This is comparable to the finding in a research carried out in Central India where only $65.75 \%$ of the women have ever heard or read about breast Cancer [8]. In contrary to the above result, research conducted in Mekelle town reported about $83.4 \%$ of the participants having heard about breast cancer [7]. And all the female students of Haramaya University of Ethiopia know about it [9]; indicating education had a great contribution for the awareness about cancer. The result revealed that women who have formal education had 8 times more likely to have good knowledge than those who do not have formal education. Major source of information about breast cancer according to this study result was media, accounting about 76 (36.9\%). This is comparable with the result of other studies, such as Mekelle (59.1\%) and Adama (41.7\%) where media is the most common source of information. But it was not sufficient in creating adequate information, where only $61.31 \%$ of the study participants had heard about cancer. Among the women who have heard about breast cancer, majority of them are classified as having poor knowledge (86.4\%). Similar figures were found on studies conducted among female students in Adama where about 91.3\% had poor knowledge on cancer [10]. In contrast, in a study done in Saudi female students in 2014 , only $29.3 \%$ of the women were labeled to have poor knowledge [11]. This high knowledge difference is explained by a better access to information and formal education, which is lacking in our county. 
According to this study, family history of breast cancer, smoking and not breast feeding are risk factors for breast cancer mostly picked by the women; $129(62.6 \%), 98(47.6 \%)$ and 86 (41.7\%) respectively, a result that resembles a finding in Hong Kong; Chinese women, where $70.8 \%$ of them considered a family history of breast cancer as a risk factor. This has Most women in our research didn't pick high fat diet (6.3\%), late menopause $(10.7 \%)$ and early menarche $(15.5 \%)$ as risk factors for breast cancer. The Hong Kong study reports that over $40 \%$ were unable to identify risk factors including old age, early menarche, late menopause and nulliparity [12]. In this study, 79.1\% of the women knew breast cancer presented as breast lump; where $76.1 \%$ of the study on Tigray undergraduate female students also depicts the same [13]; and $53.6 \%$ of female Adama university students as well [10] knew breast lump could be a symptom for breast cancer. Most women in this study as well as other studies did not think that lump under the armpit could be a sign or symptom of breast cancer. About $49.5 \%$ of the women who are informed about breast cancer believe that early detection of breast cancer improved survival. This finding is very much lower compared to that of the study in Mekelle town where it is $90.2 \%$ [7]. A contrasting result to this was reported from a study among Jordanian women where the study participants said that detecting it in an early or late state wouldn't change the course of the disease [14].

The result showed, out of the women who reported to have had breast cancer information 94(45.6\%) have ever heard about BSE, but only $13(13.8 \%)$ of those who have heard about BSE practice it. This is in line with the research report of Mekelle town where $45 \%$ of those who had information on breast cancer have ever heard/ read about BSE but only 20.1\% have ever practiced BSE [7]. This shows a comparable gap between knowledge of breast cancer and BSE and practice of BSE. Accordingly, many women do not have the practice of BSE because of awareness deficit.

On the other hand, this study showed, of those who know how to perform BSE but do not practice, most stated their reasons were: not having breast problem17 (70.8\%) and not thinking it was important $10(41.6 \%)$. In a cross-sectional survey among 357 Kuwait women, the main reasons for not performing BSE were fear of cancer discovery (13.4\%), forgetfulness (14.5\%), failure to realize the importance of BSE (15.3\%) and lack of knowledge about the technique of BSE (28.9\%) [15]. In a study conducted among Arab women in UAE about $81.6 \%$ of women practicing BSE were given instructions by a healthcare provider. This might be due to the increased early detection and awareness activities conducted by the local health authorities during the past decade; thus, offering information to women on how to perform BSE improves screening practices [15]. This statement might explain the reason for low and irregular 8(61.4\%) BSE practice in the present study as most of the women's information source is informal.
Symptom detection is the initial step in the health seeking process. Thefinding of this study revealed that out of 336 participants, $256(76.2 \%)$ women feel positive about visiting a health center for any problems they detect in their breast. Similarly based on study conducted in Nigeria women assessing the knowledge, attitude and practice towards breast cancer, there was an indication of positive health seeking behavior as a majority of the participants mentioned that visiting the doctors was the best approach for breast cancer treatment [15]. In addition to this, based on survey conducted in India on women's knowledge, attitudes, and practices about breast cancer in a rural district of central India, most urban (95.4\%) and rural $(96.4 \%)$ women were ready to visit a doctor as soon as they felt a mass in their breasts. Severity of the symptoms could strongly encourage women to seek medical help. Some women who postponed seeking medical treatment go for alternative choice of therapy such as herbal medication; fear of breast surgery is also put as the other barrier to consider alternative therapies [15]. The main reason for not seeking health facility for women not thinking it's a serious problem $32(40 \%)$ and the belief that traditional healers are better than health facilities27(33.7\%).

\section{Conclusion}

The findings of this study indicate that there is lack of appropriate information about breast cancer and early detection methods; may be due to the inability of the participants to read and write. The result shows the major source of information about breast cancer and BSE is media (television and/ or radio). Majority of women in Leku town have poor knowledge on breast cancer and also only small portion of the women have information about BSE and know how to perform BSE. Having formal education, family history of breast cancer and self-history of breast problem has significant association with knowledge about breast cancer attack. On the other hand, having good knowledge has association with BSE practice. Even though most of the women have good health seeking behavior, some women prefer traditional medicine and have negative attitude towards health care seeking. Above all, majority of them have positive attitude towards the cancer treatment which they said is given at hospital; even though the cost is not affordable.

\section{Recommendation}

As this study depicts, to fill the significant gap between the healthcare system and the community's knowledge and practice, we recommend Leku hospital and Sidama Region health bureau to work in collaboration on awareness creation program about breast cancer and its early detection methods by campaigns or by recommending health professionals to communicate more with the community and give health education for every patient available to increase a dissemination of proper information about breast cancer and BSE practice. 


\section{Acknowledgements}

We are grateful to Hawassa University, collage of medicine and health science, school of public and environmental health for allowing us to do this research paper by providing ethical clearance. At last, our gratitude goes to the participants of this study.

\section{Author's Contributions}

Lalisa Gemechu Bona, Daraje Geleta Negera and Alemu Tolcha are the Authors who designed the proposal and trained the data collectors. After data entry, we also did the write up and finalization of the paper.

\section{Conflict of Interest}

We declare that there is no conflict of interest; because this paper was not funded, presented or issued to any organization.

\section{Further Information}

This work was not funded by any organization or presented on any national or international conference. Nor it was presented on any platforms.

\section{References}

1. (2011) Ethiopian cancer association. Top ten cancer burdens classifications.

2. Kanavos P (2006) The rising burden of cancer in the developing world Ann Oncol 17 (Viii15-viii23).

3. Ashley D (2013) Stage treatment and outcomes for patients with breast cancer in British Columbia in 2002: a population-based cohort study. CMAJ OPEN 1: 135-141.

4. Alemayehu A (2011) Review on genetic and environmental factors for breast cancer: University of Gondar, college of medicine and health sciences school of biomedical and laboratory science, Gonder, Ethiopia.
5. Shewaye F (2017) Assessment of Knowledge, Attitude and Practice of Breast Self-examination among Ambo University Undergraduate Regular Female Students. Journal of Medicine, Physiology and Biophysics. Department of Public Health, College of Medicine and Health Sciences 32. Ambo, Ethiopia.

6. Befikadu L, Teferi G (2014) Knowledge on breast cancer and its prevention among women household heads in Northern Ethiopia. OJPM 4: $30-40$.

7. Nitin G, Nawi N, Miguel S (2015) Women's knowledge, attitudes, and practices about breast cancer in a rural district of Central India. Asian Pac J Cancer Prev 16: 6863-6870.

8. Kalandar Ameer, Salah Mohammed Abdulie, Sanjoy Pal, Khalid Arebo, Gebrehiwot gebretsadik Kassa (2014) Breast cancer awareness and practice of breast self-examination among female medical students in Haramaya University. Int. J. Interd and Multidisc Stud (IJIMS) 2: 109-119.

9. Segni M, Tadesse D, Amdemichael R, Demissie H (2016) Breast Selfexamination: Knowledge, Attitude, and Practice among Female Health Science Students at Adama Science and Technology University, Ethiopia. Gynecol Obstet (Sunnyvale) 6: 1-6.

10. Rabia L (2014) Knowledge and attitude of Saudi female students towards breast cancer: A cross-sectional study. J of Taibah Uni Med Sci 9: 328-334.

11. Haftom G, Tesfay H, Gebreamlak G (2014) Knowledge and attitude towards breast cancer among Mekelle University female regular undergraduate students, Tigray Region, Ethiopia. Sch J App Med Sci 2: 766-772.

12. Petro NW, Mikhail BI (2002) Factors associated with BSE among Jordanian women. Public Health Nursing 19: 263-271.

13.Al- Qattan MM, Al Saleh KA, Al-Musallam SS, Masoud GM (2008) Knowledge and factors affecting BSE among Kuwaiti women.

14. Elobaid YE, Aw TC, Grivna M, Nagelkerke N (2014) Breast Cancer Screening awareness, Knowledge, and Practice among Arab Women in the United Arab Emirates: A Cross-Sectional Survey. Plos One 9: 1-6.

15. Michael N, Clareann H, Friday E, Usifo, O (2006) Knowledge attitude and practice of Nigerian women towards breast cancer; A cross sectional Study. World J of Surg Onco 4: 1-9.

\section{ISSN: 2574-1241}

DOI: 10.26717/BJSTR.2021.36.005911

Lalisa Gemechu Bona. Biomed J Sci \& Tech Res

(C) (P) This work is licensed under Creative

Submission Link: https://biomedres.us/submit-manuscript.php
Commons Attribution 4.0 License

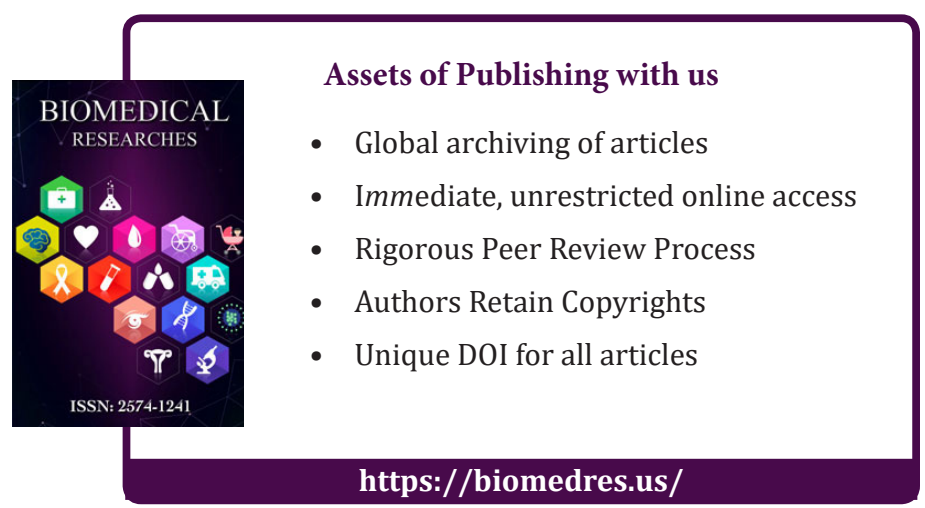

